\title{
ANALISIS VIDEO LIKES TO FOLLOWERS TIKTOK PADA 5 MOBIL TERMEWAH DI DUNIA
}

\author{
Kadek Krisna Wedayana Aditya Putra krisnaweda73@gmail.com
}

\begin{abstract}
TikTok is a social media platform that was launched by a Chinese company. TikTok lets its user to create a 15 seconds video which features music, filters, or other creative fitures. Tiktok has over 1 million active users in the world, making it one of the world's biggest social media platform. The large number of active TikTok users in the world can certainly provide an opportunity for brands to make TikTok a social media marketing platform. Luxury car brands also uses TikTok as a tool for marketing, McLaren, Rolls Royce, Lamborghini, Bugatti, and Ferrari are five of them. The purpose of this study is to calculate the credibility of the TikTok account performance of the five previously mentioned luxury car brands. The method used for this research is quantitative exploratory method. The result of this research indicates that the luxury car brand Rolls Royce is ranked first and has good account performance credibility.
\end{abstract}

\begin{abstract}
ABSTRAK
TikTok merupakan platform sosial media yang diluncurkan oleh perusahaan asal Tiongkok. TikTok memungkinkan penggunanya membuat video berdurasi 15 detik yang disertai dengan musik, filter, dan beberapa fitur kreatif lainnya. TikTok memiliki lebih dari 1 Miliar pengguna yang aktif di Dunia dan menjadikan tiktok sebagai salah satu platform media sosial terbesar di Dunia. Maraknya jumlah pengguna TikTok yang aktif di Dunia tentu dapat memberikan peluang bagi brand untuk menjadikan TikTok sebagai platform pemasaran media sosial. Merek-merek mobil mewah juga menggunakan TikTok sebagai alat pemasaran. Lima diantaranya adalah McLaren, Rolls Royce, Lamborghini, Bugatti, dan Ferrari. Tujuan dari penelitian ini yaitu untuk menghitung kredibilitas dari performa akun TikTok dari kelima merek Brand Mobil Mewah yang disebutkan sebelumnya. Metode yang digunakan untuk penelitian ini yaitu metode eksploratif kuantitatif. Hasil dari penelitian ini menunjukan bahwa brand mobil Rolls Royce mendapatkan peringkat pertama dan memiliki kredibilitas performa akun yang baik.
\end{abstract}

Keyword : Credibility Account TikTok ; Social Media Marketing ; Social Media TikTok ; Video Likes to Followers Ratio ; Mobil Termewah. 


\section{PENDAHULUAN}

Perkembangan teknologi yang semakin pesat membawa perubahan yang besar dalam kehidupan manusia baik dari sisi sosial maupun budaya. Menurut Nuryanto (2012:1) Perkembangan teknologi dalam hal informasi begitu sangat berkembang salah satu buktinya dengan mudahnya kita dapat mengakses informasi dimanapun dan kapanpun dengan jaringan internet tersebar luas di mana-mana, dalam sumber. Dengan perkembangan teknologi yang begitu pesat, memunculkan berbagai jenis akses jejaring sosial yang memberikan kemudahan dalam berkomunikasi satu dengan yang lainnya. Menurut Nasrullah (2017:8) media sosial mengajak siapa saja yang tertarik untuk berpartisipasi dengan memberi kontribusi dan feedback secara terbuka, memberi komentar, serta membagi informasi dalam waktu yang cepat dan tak terbatas. Media sosial menjadi kebutuhan penting dalam hidup manusia saat ini selain menjadi tempat interaksi sosial serta untuk memperluas jejaring sosial. Aplikasi yang akan dibahas dalam penelitian ini yaitu aplikasi TikTok merupakan aplikasi media sosial terbaru yang memungkinkan pengguna untuk membuat berbagai video menarik, berinteraksi di kolom komentar maupun chat pribadi (Deriyanto \& Qorib, 2019).

Pada tahun 2021 ini di Indonesia, sosial media yang mengalami perkembangan pesat hingga menjadi budaya populer di Indonesia adalah aplikasi TikTok. Sebenarnya aplikasi TikTok bukanlah sosial media yang baru di Indonesia, karena pada beberapa tahun belakangan di tahun 2018 hingga 2019 TikTok sudah mulai dikenal di Indonesia, akan tetapi pada saat itu TikTok kadung menjadi aplikasi digital berbasis video yang mengeluarkan output yang sifatnya membodohkan. Bahkan, fenomena internet mengamini itu saat pengguna mengetik 'aplikasi bodoh' pada kolom alamat yang kosong (Hasiholan et al., 2020).

Disamping itu, kehadiran media sosial TikTok juga dapat membangun sebuah brand, TikTok juga dapat membangun personal branding pemiliknya (Ishihara and Oktavianti 2021). Di Dunia terdapat lebih dari 1 Miliar pengguna TikTok yang aktif. Maraknya jumlah pengguna TikTok aktif tentu dapat memberikan peluang bagi brand untuk menjadikan platform ini sebagai platform social media marketing mereka. Cukup banyak akun perusahaan-perusahaan terkenal yang ada pada tiktok, contohnya seperti brand mobil-mobil mewah. Adapun Top 5 Brand Mobil Termewah di Dunia, diantaranya yaitu : Lamborghini, McLaren, Rolls Royce, Ferrari, Bugatti. Penelitian ini menggunakan metode eksploratif kuantitatif, dan akan menghitung menggunakan rasio-rasio yang ada pada TikTok. Pada penelitian (Permana and Meinarni 2021) menjelaskan bahwa terdapat 17 rasio yang ada pada sosial media TikTok dan relevan digunakan sebagai media ukur kredibilitas akun yang ada. Penelitian ini hanya berfokus untuk menghitung kredibilitas Video Likes to Followers Ratio pada Top 5 Brand Mobil Mewah di Dunia yang diantaranya yaitu; Lamborghini, McLaren, Rolls Royce, Ferrari, Bugatti (5 Deretan Mobil Termewah Di Dunia Tahun 2021, n.d.). Tujuan dari penelitian ini adalah mengetahui kredibilitas performa dari akun TikTok Top 5 Brand Mobil Mewah di Dunia menggunakan Video Likes to Followers Ratio.

\section{TINJAUAN PUSTAKA}

Perkembangan bidang teknologi saat ini terjadi begitu pesat. Melalui perkembangan yang terjadi dari waktu ke waktu menimbulkan maraknya aplikasi - aplikasi serta platform media sosial 
yang bermunculan. Aplikasi yang sangat diminati oleh masyarakat saat ini diantaranya adalah TikTok, Instagram, Twitter, WhatsApp dan yang lain sebagainya. Seiring berjalannya waktu, aplikasi sosial media tersebut dapat menjadi candu bagi kalangan masyarakat. Tidak hanya kalangan remaja yang menggunakan aplikasi sosial media, orang tua bahkan anak-anak juga aktif menggunakan aplikasi sosial media tersebut. Tiktok merupakan bagian dari new media yang memiliki perkembangan terpesat dibandingkan dengan kategori new media yang lainnya seperti facebook, Instagram, YouTube, dan Twitter (P3M STMIK Widya Cipta Dharma n.d.) .

TikTok digunakan sebagai sarana promosi yang dapat memberikan informasi yang tidak memerlukan biaya yang tinggi, tidak memerlukan tenaga yang banyak dan dapat dilakukan dalam waktu yang singkat. TikTok menjadi salah satu platform yang sedang sangat digemari saat ini. Sebagai salah satu media sosial TikTok memberikan sarana berbagi konten yang sangat bervariasi dari segi kreativitas, video challenge, lipsync, lagu, menari, bernyanyi dan lain lain. Karena banyaknya yang menggunakan maka TikTok memberikan peluang sebagai sarana promosi. Strategi marketing yang dapat dilakukan dengan platform TikTok antara lain: (a). menggunakan hashtag : hashtag (\#) sebuah tanda yang memiliki maksud agar suatu pokok bahasan, peristiwa, bahkan sebuah produk dapat mudah ditemukan. Dengan hashtag yang diberikan/digunakan dapat membantu konsumen mencari produk yang dicarinya/dibutuhkannya. (b). mengikuti tren yang terjadi : strategi pemasaran dengan menggunakan TikTok mengandalkan video yang menggambarkan hal yang sedang tren. Untuk kondisi ini produsen harus dapat menemukan moment yang sesuai untuk produknya untuk dapat dipromosikan dan dikenalkan ke konsumen. (c). melakukan kolaborasi dengan para influencer : hal ini dapat dilakukan dengan melakukan kolaborasi dengan influencer yang sedang digemari dan memiliki banyak pengikut sehingga strategi promosi yang dilakukan lewat Tik Tok dapat memikat dan menarik banyak orang. Dengan catatan tujuan pasar yang ingin dituju jelas. (d). memberikan deskripsi yang jelas : seseorang akan tertarik pada sebuah video selain dari konten nya yang bagus juga terdapat deskripsi/info produk yang disampaikan jelas. Sehingga konsumen akan memahami konten yang disampaikan lebih jelas. (e). sering memposting video dan dapat disela dengan iklan. Strategi ini dilakukan dengan melakukan upload/posting video secara rutin sehingga lebih banyak orang yang akan melihat/mengunjungi akun produk kita. Semakin banyak video yang diunggah maka membuka peluang konsumen untuk menonton dan jika sudah semakin banyak konten anda dilihat maka strategi yang lain adalah dapat diberikan iklan sehingga promosi yang anda tawarkan dapat dilakukan dan ditargetkan (Kasus et al., 2021) .

TikTok dirasakan memiliki kekuatan ataupun pengaruh dalam industri, sehingga menimbulkan kualitas akun yang menentukan strata maupun kredibilitas pemilik akun. Kredibilitas akun TikTok merupakan suatu hal yang cukup penting untuk berbagai kepentingan. Kredibilitas sebuah akun TikTok dapat diukur dari tingkat performa yang dihasilkan secara matematis. Dalam mengukur performa diperlukan skala pengukuran yang tertuang ke dalam rasio (I Putu Hendika Permana \& Ni Putu Suci Meinarni, 2021) . 


\section{METODE PENELITIAN}

Penelitian ini menggunakan metode eksploratif kuantitatif untuk mengetahui kredibilitas dari performa akun TikTok 5 brand mobil termewah di Dunia Q1 2021. Metode eksploratif merupakan penelitian yang memiliki tujuan untuk melakukan eksplorasi atau memperdalam pengetahuan ataupun ide-ide baru mengenai suatu hal yang baru, guna merumuskan permasalahan secara terperinci (Maryam, Isrok'atun, and Aeni 2016) .

Tujuan dari penelitian ini yaitu mengetahui nilai kredibilitas dari performa akun TikTok 5 brand mobil termewah di Dunia Q1 2021. Ada beberapa langkah yang harus dilakukan dalam penelitian ini, sehingga mampu menemukan peringkat pertama akun TikTok brand mobil termewah di Dunia yang memiliki performa terbaik. Langkah-langkah yang dilakukan pada penelitian ini, diantaranya yaitu :

\section{Melakukan Eksplorasi Pada Website Untuk Menentukan Objek yang Akan Dianalisa.}

Eksplorasi ini dilakukan pada beberapa halaman website yang menyediakan informasi mengenai objek yang akan diteliti. Setelah eksplorasi selesai dilakukan, sehingga ditemukan nama-nama mobil termewah di Dunia yang akan dijadikan objek analisa. Setelah melakukan eksplorasi pada halaman website, maka langkah selanjutnya yaitu mencari nama akun TikTok dari masing-masing brand mobil. Pastikan semua vendor memiliki akun pada aplikasi sosial media TikTok.

2. Menghitung Nilai Rata-Rata Variabel Dari Top 5 brand mobil termewah di Dunia. Pada langkah ini, peneliti menghitung nilai variabel video likes dan followers. Variabel merupakan sesuatu yang memiliki nilai bervariasi dimana nilai tersebut dapat dijadikan sebagai dasar untuk empat data yang berbeda seperti rasio, skala, ordinal, nominal dan internal (Rankuti 2015) . Untuk menghitung nilai rata-rata dari variabel video likes dan followers yaitu dengan cara mengambil minimal 10 postingan video kemudian dihitung sehingga menemukan nilai rata-rata.

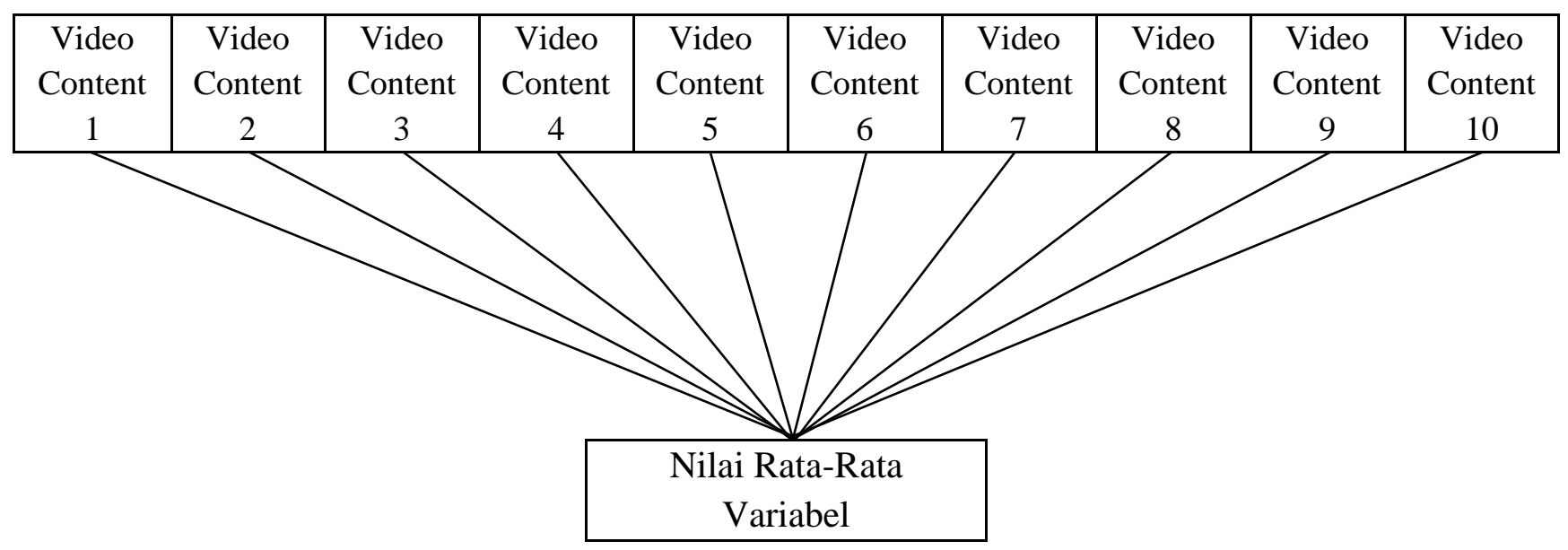

Gambar 1. Analisa Nilai Rata-Rata Variabel. 


\section{Menghitung Nilai Kredibilitas Rasio}

Untuk menghitung nilai kredibilitas dari video likes to followers ratio, peneliti menggunakan cara membagi nilai variabel pertama dengan nilai variabel kedua. Jika video likes memiliki nilai 100 dan followers memiliki nilai 300, maka cara menghitungnya yaitu $100: 300=0,3$. Dengan begitu nilai dari video likes to followers ratio adalah 0,3.

\section{Menentukan Peringkat Pada Akun TikTok}

Pada langkah terakhir yang dilakukan pada penelitian ini yaitu menentukan peringkat pada masing-masing rasio yang ada. Pada penentuan peringkat perlu melihat karakteristik dari rasio yang diteliti. Jika karakteristik rasio merupakan rendah, maka objek yang memiliki nilai terendah akan mendapatkan angka 5 dan objek yang memiliki nilai tertinggi akan mendapatkan angka 1. Namun jika rasio memiliki karakteristik tinggi maka objek yang mendapatkan nilai tinggi akan mendapatkan angka 5 dan objek yang mendapatkan nilai terendah akan mendapatkan angka 1 . Setelah mendapatkan hasil kredibilitas ratio maka dapat disimpulkan objek yang mana mendapatkan peringkat 1 sampai dengan peringkat 5 .

\section{HASIL DAN PEMBAHASAN}

Akun TikTok dari Top 5 Mobil Termewah di Dunia Q1-2021, diantaranya: 1.

\section{Lamborghini}

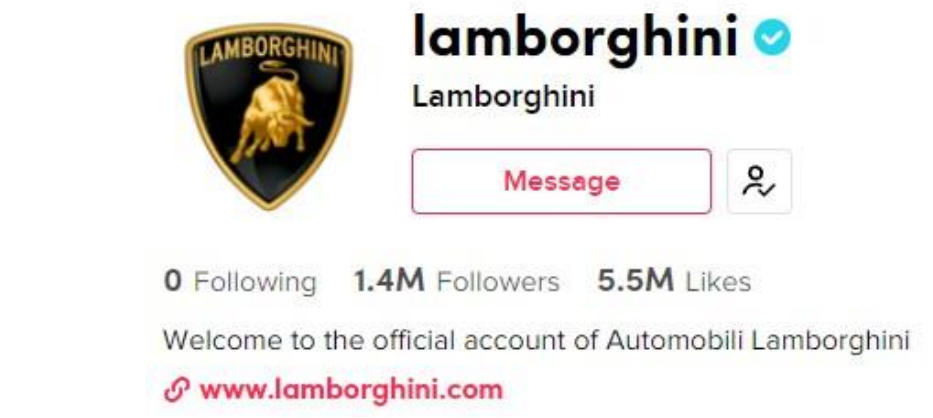

https://www.tiktok.com/@lamborghini (akses pada tanggal 21-10-2021)

\section{McLaren}

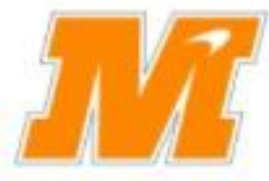

mclaren

McLaren

Message

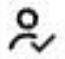

8 Following 1.4M Followers 26.8M Likes

TikTokin' on track

$\mathcal{N}$ www.mclaren.com/racing/

https://www.tiktok.com/@mclaren (akses pada tanggal 21-10-2021) 


\section{Rolls Royce}

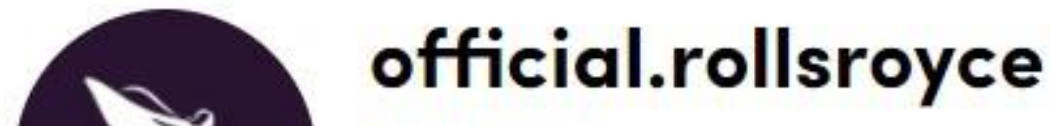

Rolls Royce

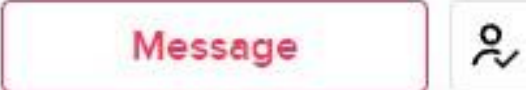

\section{Following $\mathbf{4 5 4 8}$ Followers $\mathbf{2 7 2}$ Likes}

Here are the best facts about the new Roll Royce Car's https://www.tiktok.com/@official.rollsroyce (akses pada tanggal 21-10-2021)

\section{Ferrari}

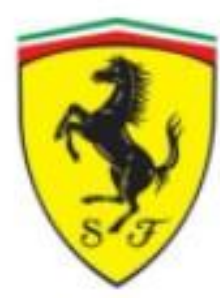

\section{ferrariclub}

\section{Ferrari}

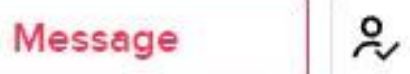

\section{Following 264.2K Followers $1 \mathrm{M}$ Likes}

Ferrari Club Worldwide

No Affiliation with Ferrari

Best Ferrari Feed

https://www.tiktok.com/@ ferrariclub (akses pada tanggal 21-10-2021)

\section{Bugatti}

\section{bugattis}

\section{BUGATTI \\ Bugatti}

\section{Message}

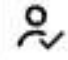

\section{Following 25.9K Followers 93.4K Likes}

"If comparable, it is no longer Bugatti."

https://www.tiktok.com/@bugattis (akses pada tanggal 21-10-2021) 
Dari kelima akun TikTok Top 5 Mobil Termewah di Dunia Q1-2021, peneliti menemukan nilai dari masing-masing variabel yang ada untuk menghitung rasio Video Likes to Followers dari setiap akun. Pada akun TikTok terdapat 7 variabel, diantaranya yaitu :

1. Likes

2. Followers

3. Following

4. Video Likes

5. Video Comments

6. Video Share

7. Video Views

Dari ketujuh variabel tersebut peneliti hanya fokus untuk menemukan hasil dari 2 variabel, yaitu:

1. Video Likes

2. Followers

Dari kedua variabel tersebut kemudian dianalisa sehingga menemukan nilai rata-rata dari variabel video likes dan jumlah followers. Untuk menghitung nilai rata-rata dari variabel video likes dan followers yaitu dengan cara mengambil minimal 10 postingan kemudian dibagi dengan jumlah followers sehingga menemukan nilai rata-rata dari total video likes dan followers. Berikut merupakan tabel nilai rata-rata dari masing-masing brand mobil termewah di Dunia, yaitu:

Tabel 1. Analisa Nilai Rata-Rata Variabel Video Likes dan Followers Akun TikTok

\begin{tabular}{|c|c|}
\hline \multicolumn{2}{|c|}{ Lamborghini } \\
\hline No & Video Likes \\
\hline 1 & 256,600 \\
\hline 2 & 21,600 \\
\hline 3 & 164,600 \\
\hline 4 & 24,600 \\
\hline 5 & 21,200 \\
\hline 6 & 17,700 \\
\hline 7 & 51,400 \\
\hline 8 & 41,600 \\
\hline 9 & 40,900 \\
\hline 10 & 41,600 \\
\hline Rata-rata & 68,180 \\
\hline Followers & $1,400,000$ \\
\hline
\end{tabular}

Sumber : Pengolah Data Excel 
Tabel 2. Analisa Nilai Rata-Rata Variabel Video Likes dan Followers Akun TikTok McLaren

\begin{tabular}{|c|c|}
\hline No & Video Likes \\
\hline 1 & 68,400 \\
\hline 2 & 46,500 \\
\hline 3 & 52,500 \\
\hline 4 & 26,500 \\
\hline 5 & 55,500 \\
\hline 6 & 24,800 \\
\hline 7 & 87,700 \\
\hline 8 & 65,000 \\
\hline 9 & 69,200 \\
\hline 10 & 97,400 \\
\hline Rata-rata & 59,350 \\
\hline Followers & $1,400,000$ \\
\hline
\end{tabular}

Sumber : Pengolah Data Excel

Tabel 3. Analisa Nilai Rata-Rata Variabel Video Likes dan Followers Akun TikTok Rolls

\begin{tabular}{|c|c|}
\hline \multicolumn{2}{|c|}{ Royce } \\
\hline No & Video Likes \\
\hline 1 & 105 \\
\hline 2 & 72 \\
\hline 3 & 96 \\
\hline Rata-rata & 91 \\
\hline Followers & 4,553 \\
\hline
\end{tabular}

Sumber : Pengolah Data Excel

Tabel 4. Analisa Nilai Rata-Rata Variabel Video Likes dan Followers Akun TikTok Ferrari

\begin{tabular}{|c|c|}
\hline No & Video Likes \\
\hline 1 & 5,576 \\
\hline 2 & 5,181 \\
\hline 3 & 5,610 \\
\hline 4 & 2,703 \\
\hline 5 & 2,071 \\
\hline
\end{tabular}




\begin{tabular}{|c|c|}
\hline 6 & 2,813 \\
\hline 7 & 1,583 \\
\hline 8 & 2,839 \\
\hline 9 & 2,028 \\
\hline 10 & 19,100 \\
\hline Rata-rata & $4,950.4$ \\
\hline Followers & 264,200 \\
\hline
\end{tabular}

Sumber : Pengolah Data Excel

Tabel 5. Analisa Nilai Rata-Rata Variabel Video Likes dan Followers Akun TikTok Bugatti

\begin{tabular}{|c|c|}
\hline No & Video Likes \\
\hline 1 & 1,774 \\
\hline 2 & 1,885 \\
\hline 3 & 1,086 \\
\hline 4 & 7,880 \\
\hline 5 & 1,001 \\
\hline 6 & 910 \\
\hline 7 & 884 \\
\hline 8 & 1,947 \\
\hline 9 & 811 \\
\hline 10 & 842 \\
\hline Total & 1,902 \\
\hline Followers & 25,900 \\
\hline
\end{tabular}

Sumber : Pengolah Data Excel

Tabel 6. Nilai Variabel Pada Akun TikTok Top 5 Mobil Termewah di Dunia Q1-2021

\begin{tabular}{|l|c|c|c|c|c|}
\hline \multicolumn{1}{|c|}{ Variabel } & Lamborghini & McLaren & Rolls Royce & Ferrari & Bugatti \\
\hline Video Likes & 68180 & 59350 & 91 & 4950.4 & 1902 \\
\hline Followers & $1,400,000$ & $1,400,000$ & 4,553 & 264,200 & 25,900 \\
\hline
\end{tabular}

Pada akun TikTok terdapat 17 rasio yang relevan digunakan untuk mengukur kredibilitas pada masing-masing akun. Namun pada penelitian kali ini hanya berfokus untuk menghitung Video Likes to Followers Ratio. Untuk menghitung kredibilitas dari masing-masing akun TikTok setiap brand mobil, peneliti menghitung dengan cara : variabel 1 akan dibagi dengan variabel 2 , sehingga ditemukan hasil analisis dari rasio tersebut.

Tabel 7. Hasil Perhitungan Rasio Akun TikTok 


\begin{tabular}{|c|c|c|c|c|c|c|}
\hline No & \multicolumn{1}{|c|}{ Rasio } & Lamborghini & McLaren & $\begin{array}{c}\text { Rolls } \\
\text { Royce }\end{array}$ & Ferrari & Bugatti \\
\hline 1 & $\begin{array}{l}\text { Rasio Video Likes } \\
\text { to Followers }\end{array}$ & 0.0487 & 0.042393 & 0.019987 & 0.018737 & 0.073436 \\
\hline
\end{tabular}

Video Likes to Followers Ratio memiliki karakteristik yang tinggi, artinya semakin tinggi nilai yang dihasilkan maka semakin baik kredibilitas dari performa akun tersebut. Untuk memberikan peringkat pada masing-masing brand mobil, peneliti memberikan angka 5 kepada brand yang mendapatkan nilai tertinggi dan angka 1 untuk brand yang mendapatkan nilai terendah. Berikut merupakan tabel urutan nilai yang dihasilkan oleh masing-masing brand mobil.

Tabel 8. Nilai Rasio Akun TikTok Top 5 Mobil Termewah di Dunia Q1-2021

\begin{tabular}{|c|c|c|c|c|c|}
\hline Ratio & \multicolumn{5}{|c|}{ Nilai } \\
\hline \multirow{2}{*}{$\begin{array}{l}\text { Video Likes to } \\
\text { Followers Ratio }\end{array}$} & Lamborghini & McLaren & $\begin{array}{l}\text { Rolls } \\
\text { Royce }\end{array}$ & Ferrari & Bugatti \\
\hline & 4 & 3 & 2 & 1 & 5 \\
\hline
\end{tabular}

Dari Tabel Nilai Rasio Akun TikTok Top 5 Mobil Termewah di Dunia Q1-2021 dapat simpulkan bahwa Bugatti mendapatkan nilai tertinggi untuk rasio Video Likes to Followers. Sedangkan akun TikTok Ferrari mendapatkan nilai terendah untuk rasio ini. Jadi, pada penelitian ini Bugatti memiliki kredibilitas performa yang lebih baik dibandingkan dengan brand mobil yang lainnya.

\section{KESIMPULAN}

Tujuan dari penelitian ini adalah mengetahui kredibilitas performa dari akun TikTok Top 5 Mobil Termewah di Dunia menggunakan Video Likes to Followers Ratio. Top 5 Mobil Termewah tersebut diantaranya: Lamborghini, McLaren, Rolls Royce, Ferrari, dan Bugatti. Dari kelima brand mobil tersebut dapat disimpulkan bahwa:

1. Peringkat pertama diraih oleh brand Bugatti dengan nilai tertinggi yaitu 0.073436.

2. Peringkat kedua diraih oleh brand Lamborghini dengan nilai 0.0487.

3. Peringkat ketiga diraih oleh brand McLaren dengan nilai 0.042393 .

4. Peringkat keempat diraih oleh brand Rolls Royce dengan nilai 0.019987 .

5. Peringkat kelima diraih oleh brand Ferrari dengan nilai terendah yaitu 0.018737 . 


\section{DAFTAR PUSTAKA}

5 Deretan Mobil Termewah di Dunia Tahun 2021. (n.d.). Retrieved October 28, 2021, from https://www.cekpremi.com/blog/mobil-termewah-di-dunia/

Deriyanto, D., \& Qorib, F. (2019). PERSEPSI MAHASISWA UNIVERSITAS TRIBHUWANA TUNGGADEWI MALANG TERHADAP PENGGUNAAN APLIKASI TIK TOK. JISIP : Jurnal Ilmu Sosial Dan Ilmu Politik, 7(2), 77. https://doi.org/10.33366/JISIP.V7I2.1432

Hasiholan, T. P., Pratami, R., \& Wahid, U. (2020). PEMANFAATAN MEDIA SOSIAL TIK TOK SEBAGAI MEDIA KAMPANYE GERAKAN CUCI TANGAN DI INDONESIA UNTUK MENCEGAH COVID-19. Communiverse: Jurnal Ilmu Komunikasi, 5(2), 70-80. https://doi.org/10.36341/cmv.v5i2.1278

I Putu Hendika Permana, \& Ni Putu Suci Meinarni. (2021). Ratio Analysis on Tiktok (Social Media) for Qualitative Research Using Explorative Methods. Jurnal Ekonomi \& Bisnis JAGADITHA, 8(1), 30-38. https://doi.org/10.22225/jj.8.1.2944.30-38

Kasus, S., Tiktok, A., Informasi, S., Teknik, F., Bina, U., \& Informatika, S. (2021). Pemanfaatan Media Sosial Tiktok Sebagai Media Promosi Industri Kuliner Di Yogyakarta Pada Masa Pandemi Covid-19 Yogyakarta In The Pandemic Time Of Covid-19. 12, 65-71. https://doi.org/10.31294/khi.v12i1.10132 